\title{
Is There a Place for Dietary Fiber Supplements in Weight Management?
}

\author{
Michael R. Lyon • Veronica Kacinik
}

Published online: 13 April 2012

(C) The Author(s) 2012. This article is published with open access at Springerlink.com

\begin{abstract}
Inadequate dietary fiber intake is common in modern diets, especially in children. Epidemiological and experimental evidence point to a significant association between a lack of fiber intake and ischemic heart disease, stroke atherosclerosis, type 2 diabetes, overweight and obesity, insulin resistance, hypertension, dyslipidemia, as well as gastrointestinal disorders such as diverticulosis, irritable bowel disease, colon cancer, and cholelithiasis. The physiological effects of fiber relate to the physical properties of volume, viscosity, and water-holding capacity that the fiber imparts to food leading to important influences over the energy density of food. Beyond these physical properties, fiber directly impacts a complex array of microbiological, biochemical, and neurohormonal effects directly through modification of the kinetics of digestion and through its metabolism into constituents such as short chain fatty acids, which are both energy substrates and important enteroendocrine ligands. Of particular interest to clinicians is the important role dietary fiber plays in glucoregulation, appetite, and satiety. Supplementation of the diet with highly functional fibers may prove to play an important role in long-term obesity management.
\end{abstract}

Keywords Dietary fiber - Obesity - Appetite regulation . Glycemic index · GLP-1 · PYY · CCK · Oxyntomodulin · L-cells $\cdot$ Free fatty acid receptors $\cdot$ Bile acid receptors

\footnotetext{
M. R. Lyon · V. Kacinik

Canadian Center for Functional Medicine,

1550 United Boulevard,

Coquitlam, BC, Canada V3K 6Y2

M. R. Lyon $(\bowtie)$

Food, Nutrition and Health Program,

University of British Columbia,

1550 United Boulevard,

Coquitlam, BC, Canada V3K 6Y2

e-mail: DoctorLyon@shaw.ca
}

\section{Introduction}

The "eat less and exercise more" paradigm has proven to be of little value in the clinical management of the obese patient. Likewise, treatments that rely upon complex or rigorous dietary plans tend to result in poor long-term benefits with patients typically drifting back to their old habits once the novelty of the diet has worn off. Clinicians are increasingly assisting obese patients in the establishment of more achievable long goals, including the avoidance of further weight gain as a realistic end point in some patients. Rather than complex dietary regimens, most patients respond more favorably to incorporating eating strategies that help them achieve and maintain a sense of satiety while reducing their caloric intake. Significantly increasing the consumption of dietary fiber to reduce the caloric density of food and reduce the glycemic impact of the food is generally considered to play an important, if not essential, part of long-term weight management [1].

\section{What Is Dietary Fiber?}

Dietary fiber is a non-starch polysaccharide in (mostly) plant food that is poorly digested by humans. Based on a recent US government consensus report, fiber can exist as dietary fiber (naturally occurring in food), or functional fiber (added during the processing or preparation of food or consumed separately as a supplement) [2]. Fiber can be insoluble or soluble in water. Insoluble fibers include cellulose, hemicellulose, and lignins, whereas soluble fibers include various gums, pectins, $\beta$-glucans, oligosaccharides, resistant dextrans, and resistant starches. Chitin and chitosan are indigestible aminopolysaccharides that are found in or are derived from the exoskeletons of arthropods such as crabs and lobster, as well 
as the cell walls of most fungi, and could functionally be regarded as fiber, although they are not recognized as fiber by most regulatory authorities. The distinction between soluble and insoluble fibers is due to the chemical properties of the fiber, resulting in its tendency to absorb water. Various physicochemical properties of fiber (viscosity, water-holding capacity, cation exchange capacity, adsorption of organic materials, and fermentability) are now thought to be fundamental to its beneficial physiologic effects. The Institute of Medicine has proposed a new definition of dietary fiber that encompasses both its physical characteristics and its physiologic effects in humans [3]. A fiber's viscosity, its waterholding capacity, and its fermentability are the chief determinates of fiber's physiologic effects.

The regulatory classification of fiber varies considerably in different countries. The Codex Alimentarius Commission of the World Health Organization has defined dietary fiber upon analytic methods rather than its physical or physiologic characteristics [4].

\section{Sources}

The typical Western diet is generally lacking in sufficient dietary fiber, being composed principally of refined grains and other highly digestible sources of starch, sugar, various fats, and animal products. Children in particular are commonly fiber deficient, with daily intakes often under $5 \mathrm{~g}$ and with little soluble fiber. Likewise, many adults in Western society consume 5 to $10 \mathrm{~g}$ of fiber daily, as opposed to the 35 to $50 \mathrm{~g}$ that is considered desirable for optimal health [5]. Moreover, because most fiber in the Western diet is derived from cereal grains, the intake of viscous soluble fiber is typically inadequate.

A diet focusing on a large intake of vegetables and fruits as well as unrefined whole grains and legumes should be the foundation of a healthy lifestyle. With this "whole-foods" based diet, it is certain that dietary fiber intake will substantially increase [6]. Unfortunately, only a minority of the population, particularly children, are likely to adopt a largely whole-foods diet anytime in the near future. Because of this, efforts are underway to establish effective means to fortify the Western diet with dietary fiber through the use of functional fibers (various fibers as food additives or ingredients as well as the use of readily accepted fiber supplements).

\section{Health Effects}

There is compelling epidemiologic and experimental data associating numerous disorders, at least in part, to a lack of dietary fiber. Ischemic heart disease, stroke atherosclerosis, type 2 diabetes, overweight and obesity, insulin resistance, hypertension, dyslipidemia, as well as gastrointestinal disorders such as diverticulosis, irritable bowel disease, colon cancer, and cholelithiasis are just a few of the many conditions that seem to be influenced by the adequacy of dietary fiber intake [7, 8].

Numerous studies have demonstrated that certain fibers decrease the glycemic response to food, promote satiety, lower serum cholesterol, promote bowel regularity, positively influence colonic microflora, provide nutritional substrates for colonic mucosal cells, improve mucosal barrier function, as well as aid in the sequestration and elimination of toxic and carcinogenic dietary and environmental compounds. These and other effects constantly interplay to increase or decrease the development of a wide range of health conditions.

Viscous dietary fibers have been correlated with moderation in blood glucose and cholesterol concentrations, prolonged gastric emptying, and slower transit time through the small intestine [9]. Among viscous fibers, fermentability is mostly associated with large bowel function. Rapidly fermented fiber sources provide substrates for short-chain fatty acid (SCFA) production by microflora in the large bowel, whereas slowly or incompletely fermented fiber sources improve bowel health by promoting laxation, reducing colonic transit time, and increasing stool weight [10].

\section{Mechanisms of Action of Dietary Fiber}

Dietary fiber exerts its effects through an interaction between the physical properties it imparts to foods accompanied by a complex array of microbiological, biochemical, and neurohormonal influences. Dietary fiber can have a strong influence on the palatability of food, and may require longer periods of mastication before swallowing, thus influencing ingestive behavior. In the stomach, fiber affects the volume and viscosity of food, which has a highly significant effect on satiety [11]. This "volumetric" effect on food promotes a sense of fullness and a delay in gastric emptying, which tends to naturally result in a decrease in caloric intake. Various fibers differ dramatically in their ability to impart volume and viscosity to foods, and it has been shown that simple distention of the gastric antrum by soluble, viscous fibers leads to a sensation of satiety that tends to promote cessation of eating during meal time [12]. Viscous fiber has also been shown to slow gastric emptying, thus resulting in a prolongation of the mechanical distention of the stomach [13]. As well, viscous fiber consumption results in a delayed postprandial rise of ghrelin, the principle peripheral orexigen that promotes meal initiation. This delay in the pre-meal elevation of ghrelin is thought to result from slowed absorption of glucose and amino acids and a resultant increase in the delivery of these nutrients to the jejunum and ileum [14]. 


\section{Viscosity of Fiber}

Viscosity as related to dietary fiber refers to the ability of some polysaccharides to thicken or form gels when mixed with fluids resulting from physical entanglements and hydrophilic interactions among the polysaccharide constituents within the fluid or solution [15]. Gums, pectins, and $\beta$-glucans make up the majority of viscous dietary fibers. Apples, legumes, and oats are common dietary sources of viscous fibers. The viscosity that a fiber imparts to the gastric and small intestinal contents is directly correlated with the ability of the fiber to reduce postprandial glycemic response, promote satiety, decrease serum cholesterol, and decrease serum uric acid $[16,17 \bullet \bullet]$. The viscosity of fiber is also thought to play an important role in the augmentation of gut mucosal protection through the stimulation of enteral mucus production and goblet cell hypertrophy and replication [18]. Additionally, those viscous fibers that are largely fermented by colonic microflora exert a wide array of physiologic effects through the production of SCFAs (the principle energy substrates of colonocytes), the promotion of beneficial colonic microbial populations, and the augmentation of important gut-derived peptide hormones.

The viscosity of fiber is best measured by methods that quantify a hydrated fiber's internal friction and its ability to resist flow. Viscosity is usually expressed in units of millipascal seconds or centipoise [19]. Other factors, such as shear stress (e.g., mastication, peristalsis), acid $\mathrm{pH}$, dilution, and chemical components of food determine the real viscosity that a fiber will impart to food rather than just its in vitro viscosity.

The concept of the glycemic index (GI) came about through the work of Jenkins et al. [20] as they examined the impact of viscous fiber ingestion on glucose tolerance. It is now generally accepted that the GI of a carbohydrate-containing food is directly correlated to the viscosity of that food after ingestion. Viscous fibers increase small intestinal transit time, thus decreasing the speed of macronutrient digestion and absorption [14]. Along with changes in absorptive rate, prolonging the exposure of the enteral mucosa to macronutrients augments the liberation of anorexigenic peptides. Fat and protein in the proximal small bowel stimulate the release of cholecystokinin (CCK), which promotes acute postprandial satiety. As well, the elevated delivery of carbohydrates to the distal small intestine, stimulate the release of the anorexigenic peptides glucagonlike peptide 1 (GLP-1) and peptide YY (PYY) in a manner perhaps akin to that which occurs (on a greater scale) from the malabsorption accompanying gastric bypass surgery $[21,22 \cdot]$. These mechanisms tend to promote satiety between meals and result in a delay in the onset of hunger.

\section{Water-Holding Capacity and Energy Density}

The ability of a fiber to absorb and hold on to water as it transits the gut is key factor that contributes to its functional effects. Soluble fibers have the capacity to create a stable gel that results in stomach volume being occupied and a sense of satiety created without the addition of significant calories. This concept has been referred to as "caloric displacement," meaning that the consumption of low-calorie-density food or supplemental fiber can result in the achievement of satiety with a caloric intake that is less than if the food consumed was higher in caloric or energy density.

A food's energy density consists of the net quantity of calories in a particular weight of food (usually expressed as $\mathrm{kcal} / \mathrm{g}$ ). Several strategies have been employed involving the addition of substantial amounts of low-energydensity foods to a meal plan. For instance, consuming a high-fiber, low-energy-density soup as a "preload" before the rest of a meal significantly reduces the ad libitum food intake for that meal while increasing feelings of satiety [23]. Similarly, consuming a large, low-energydensity salad at the onset or during a meal reduces the total ad libitum consumption of food for that meal [24••]. Recently, it has been demonstrated that a variety of highfiber vegetables can be added to acceptable foods resulting in a significant decrease in the calorie density of the food without a negative impact upon the palatability of the food, even with children [25••]. Consuming functional fiber supplements prior to or with meals can also reduce the caloric density of meals and promote satiety. As an example, our research group recently studied the effect of adding a highly viscous functional fiber supplement $\left(\mathrm{PGX}^{\circledR}\right)$ to each meal with food, or in liquid meal replacements in women on a low-calorie diet. In this double-blind placebo-controlled trial, each 5-g dose of the highly viscous fiber was estimated to hold approximately $1 \mathrm{~L}$ of water in its passage through the stomach and small intestine, essentially adding $3 \mathrm{~L}$ or over $6 \mathrm{lb}$ of non-caloric food mass to the daily food intake. In this study we were able to show that the viscous fiber supplement significantly reduced hunger feelings and promoted satiety during a period of significant caloric reduction (Fig. 1) [26••].

Those who work in the field of obesity management generally accept the necessity of teaching patients practical strategies that promote the consumption of lowcalorie-density, highly volumetric foods in the dietary management of overweight and obesity [27••, 28, 29]. Functional fiber supplements may play a significant role in assisting patients in the achievement of consistent reductions in the energy density of their diets, especially during periods of significant caloric reduction. 


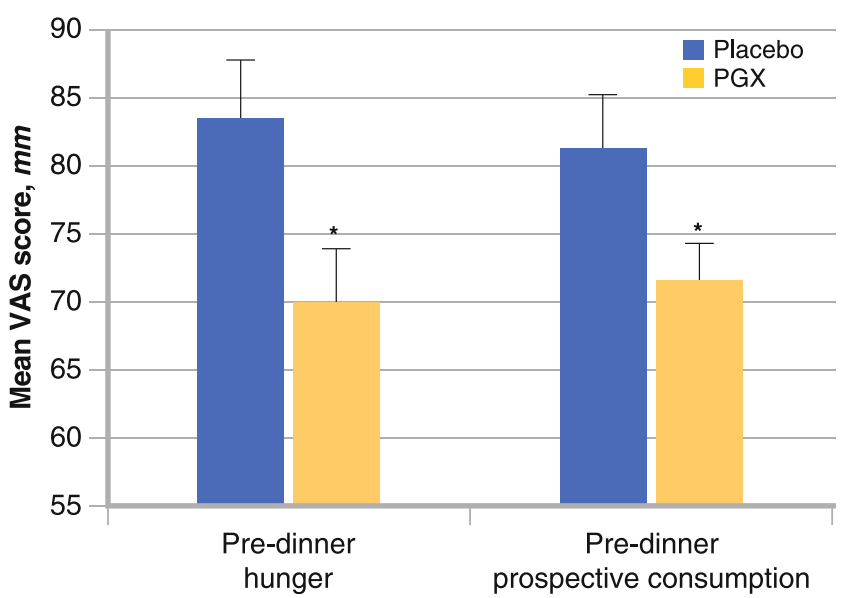

Fig. 1 Comparison of pre-dinner mean hunger and prospective consumption scores of day 3 of the 1000-calorie diet supplement with $5 \mathrm{~g}$ of PGX or placebo at each meal. Values are mean \pm SE $(n=35)$. Asterisk $\left(^{*}\right)$ indicates significantly lower scores with PGX than the placebo supplement $(P<0.05)$. VAS - visual analogue scale

\section{Prebiotic Effects of Fiber}

It is increasingly recognized that certain forms of fiber are fermentable, providing important metabolic substrates in the metabolism of gut flora. By definition, humans lack the enzymes specific to digest fiber. In the case of insoluble fiber, most gut microbes cannot utilize this as an energy source, and so it is typically excreted without any molecular alteration other than by forming a surface for the adsorption of water, organic matter, and cations. Soluble fibers vary in their fermentability and in the specific microbes that can utilize them as substrates. The term "prebiotic" was coined by Gibson and Roberfroid [30, 31] in 1995, and was defined as an indigestible carbohydrate that is fermentable in the lower gastrointestinal tract that selectively promotes the growth of desirable (prebiotic) microflora and is associated with a positive health outcome. Although there may be exceptions, prebiotics tend to reduce populations of potentially pathogenic flora while promoting desirable commensals such as Bifidobacteria.

Recent evidence suggested that this effect might play an important role in both the reduction in adiposity as well as a decline in the contribution of adipocytes to inflammation. It has been demonstrated in animal models that prebiotic supplementation might reduce the development of large adipocytes (those that predominate in the visceral compartment), which are highly involved in the overactivation of a wide variety of inflammatory processes associated with overeating, obesity, diabetes, cardiovascular disease, and pain [32,33].

Pathways of inflammation associated with atopic disease may also be intimately associated with gut flora. Both probiotics and prebiotics are believed to hold significant promise in the prevention and treatment of allergies and atopic disorders, such as eczema [34-37], and they may have the potential to play a significant role in the management of inflammation as it relates to metabolic syndrome and other obesity-related comorbidities such as nonalcoholic steatohepatosis [38, 39].

Lack of sufficient intake of prebiotics early in life may have lasting ill effects on glucoregulation, which may result in a substantial predilection toward obesity, diabetes, and cardiovascular disease later in life [40]. Unfortunately, there is little effort being made to increase fermentable soluble fiber intake in infants and children. This may have serious consequences and may be one of the many reasons for the current obesity epidemic. The food industry has just begun to respond to this with the introduction of prebiotic-fortified infant formulas. Because breast milk contains significant quantities of prebiotic oligosaccharides, adding analogous agents to infant formulas would help these formulas to more closely mimic breast milk. This strategy results in a gut flora predominated by Bifidobacteria, rather than potential pathogens such as Clostridia and Enterobacter that tend to predominate in formula-fed infants [41]. There is now a growing body of evidence that alterations in gut flora (eg, a relative absence of Bifidobacteria) are significantly associated with obesity [42]. In this regard, prebiotic fiber supplementation may play a clinically important role in the promotion of a more desirable gut microbiological milieu.

\section{Neuroendocrine Effects of Fiber}

One of the most intriguing and rapidly unfolding discoveries is related to the role played by dietary fiber in the modulation of important neuroendocrine physiology, which may be related fundamentally to the etiology of obesity and related conditions. Of particular interest is the impact of fiber on the density and activity of a specialized enteroendocrine cell known as the $\mathrm{L}$ cell [43]. The $\mathrm{L}$ cell is located throughout the terminal ileum and colon, and it is responsible for the secretion of the peptide hormones GLP-1, PYY, and oxyntomodulin [44]. After a meal, oxyntomodulin and PYY are released synchronously and they both act as potent anorexigens. The rapid rise of these peptides signals a change in energy status to the brain and it also acts locally to enhance digestive and metabolic processes. GLP-1 is an incretin hormone that also plays a pivotal role in glucoregulation through the stimulation of accurately timed insulin secretion and suppression of inappropriate glucagon secretion from the pancreas. It has been established that diminished GLP-1 production plays a central role in the etiology of diabetes, a discovery that has led to the development of an important class of diabetes drugs, the incretin analogues. Augmentation of PYY and GLP-1 are thought to play a central role in the regulation of the "ileal brake." The ileal brake is a 
feedback mechanism that results in inhibition of proximal gastrointestinal motility and secretion when nutrients and nutrient metabolites arrive in sufficient quantities to the luminal surface of the ileum. Animal and human studies show that activation of the ileal brake by local perfusion of the ileum with nutrients increases feelings of satiety and reduces ad libitum food intake while slowing gastric and proximal intestinal transit [45].

It has been recently shown that (bariatric) gastric bypass surgery frequently results in rapid amelioration of diabetes that often precedes significant weight loss [46]. Current evidence points to a rapid and sustained increase in circulating GLP-1 and PYY after this procedure that has profound effects on appetite and glucoregulation. It is now thought that the malabsorption of macronutrients and rapid gastrointestinal transit after gastric bypass results in an increased delivery of carbohydrates and their fermentation products (SCFAs) as well as bile acids, both of which activate L cells via free fatty acid (FFA) receptors and bile acid receptors [47-51].

It is most interesting that fermentable soluble fiber has the potential to generate a significant supply of SCFAs that might mimic, on a lesser scale, the mechanism of gastric bypass surgery through stimulation of FFA receptors with a resultant increase in GLP-1 and PYY and augmenting the ileal brake [52-54]. Viscous soluble fiber also effectively sequesters bile acids, reducing their usual absorption through the jejunum and delivering them to the same L cells where they stimulate bile acid receptors. Thus, viscous soluble fiber that is also fermentable may exert an appetite-reducing and glucoregulating effect through L-cell activation via both FFA receptors and bile acid receptors as well as by suppression of the orexigenic (appetite-stimulating) hormone ghrelin and augmentation of CCK secretion [55-57].

Sequestration of bile acids by viscous soluble fiber is also known to be a principle mechanism by which viscous fiber lowers serum cholesterol, because sequestration of bile acids decreases the enterohepatic recycling of bile acids, a major cholesterol reservoir for the human [58].

\section{Effect of Fiber on Postprandial Glycemia}

Dietary recommendations for weight management usually include advice regarding the quantity of carbohydrates or the percentage of daily calories from carbohydrate-containing foods. A more meaningful recommendation might be based upon the GI (the quantitative effect of a food on postprandial glycemia) and the glycemic load (GL; the mathematical product of the GI and carbohydrate content). The GI of carbohydratecontaining foods has long been known to be directly related to the quantity and form of dietary fiber in the food [59]. Recently, it has been verified that the GI and GL are more important determinants of glycemic and insulinemic response than that of carbohydrate intake alone $[60,61]$. This may have profound implications in the management of obesity and related conditions. In diabetes, continuous glucose monitoring has confirmed that GI and GL predict glycemic variability independent from total carbohydrate intake [62].

Low GI-based diets have been shown to promote satiety and reduce postprandial insulinemia [63]. However, the evidence in favor of low GI/GL is inconsistent with many weight loss studies showing only a trend in favor of this approach [64]. Long-term adherence to a low GI diet may be part of the problem in some studies. Regular use of viscous fiber supplements may help obese subjects to consistently achieve a lower GL while eating a diet that they can reasonably maintain.

Maintenance of weight after weight loss interventions is an elusive goal that has recently become the focus of several important studies. The Diogenes (Diet, Obesity, and Genes) study was designed to assess the efficacy of moderated fat diets that vary in protein content and GI in the prevention of weight regain and obesity-related risk factors after weight loss [65••]. In this trial, the group maintained on the low GI diet with moderately higher protein $(25 \%$ of calories from protein) had the highest compliance, the lowest dropout rate, and was the only group that did not regain weight by the end of the 26-week weight maintenance intervention period. Data from the same study concluded that the low GI diets also had a more substantial effect on the reduction of inflammation (as evidenced by C-reactive protein) than the other diet interventions [66]. This finding is in keeping with other studies pointing to a substantial benefit of dietary fiber in the reduction of CRP, oxidative stress, and proinflammatory cytokines [67-69].

The consistent addition of functional fiber supplements to the diet may present a practical means to achieve meaningful reductions in the GI/GL. Recently, our research group was involved in several studies looking at the effects of adding a novel, highly viscous functional fiber supplement $\left(\mathrm{PGX}^{\circledR}\right)$ to various foods on GI, serum cholesterol [71], hunger, and satiety in healthy humans $[26 \bullet \bullet, 71 \bullet \bullet, 72,73 \bullet \bullet, 74,75]$. The novelty of this fiber relates to its viscosity, which is higher than other fibers thus studied and the fact that its viscosity slowly evolves once hydrated. This allows consumption before palatability is significantly affected. This viscous fiber is fermentable and prebiotic [76] and it is tasteless, and disperses readily when added to food or mixed with beverages. Its viscosity develops several minutes after initial hydration, making it easy to consume the small amounts needed to create a highly viscous and volumetric gastric milieu, leading to its resultant physiologic effects.

In several studies, we have shown that the GI of food can be substantially reduced with a small preload or 
intra-meal load of this highly viscous fiber $[71 \bullet \bullet, 72$, $73 \bullet \bullet, 75]$. It has also been shown to promote satiety and reduce subsequent food consumption [25••]. In a human clinical trial, this novel viscous fiber has been associated with an increase in the appetite-reducing hormone PYY [77]. In studies of Zucker diabetic fatty rats, the effects of diets supplemented with this highly viscous fiber were compared with other dietary fibers. Only the diet supplemented with the highly viscous fiber substantially decreased postprandial blood glucose and insulin secretion, decreased hepatic fatty infiltration, and preserved pancreatic $\beta$-cell mass [78]. These effects were accompanied by an increase in the production of the glucoregulatory incretin hormone GLP-1 [79].

\section{Recommended Intake of Fiber for Weight Management}

The dietary fiber intake for typical Americans is usually less than desirable, with typical intakes averaging only 14 to $15 \mathrm{~g}$ /day and children consuming less than $5 \mathrm{~g}$ /day [4]. The American Dietetic Association currently recommends that healthy adults should consume 20 to $35 \mathrm{~g}$ of fiber per day and children should consume at least $5 \mathrm{~g}$ /day plus $1 \mathrm{~g}$ for every year of their age [80]. They point out that insoluble, nonfermentable, and low-viscosity fiber is principally consumed to promote laxation and other aspects of colon health, whereas viscous soluble fibers are necessary to reduce serum cholesterol, blunt postprandial glycemic response, and promote satiety. A fiber-rich meal, particularly a meal high in viscous, soluble fiber, is processed more slowly, promoting earlier satiety, and is frequently less calorically dense and lower in fat and added sugars. All of these characteristics are typical of a dietary profile optimized to treat and prevent obesity. In one study, consisting of 252 middle-aged women it was observed that over a 20 -month period participants lost an average of $4.4 \mathrm{lb}$ in association with an 8-g increase in dietary fiber per $1000 \mathrm{kcal}$ [81]. Likewise, in a prospective cohort study of nearly 30,000 men, a dose-response relationship was found between fiber intake and weight gain over a period of 8 years. They reported that for every $40-\mathrm{g} / \mathrm{d}$ increase in whole-grain intake, weight gain decreased by $1.1 \mathrm{lb}$. Moreover, the addition of supplemental bran seemed to play an important role in the reduction of weight gain by $0.8 \mathrm{lb}$ per $20 \mathrm{~g} / \mathrm{d}$ intake [82]. Pal et al. [83・•] at Curtin University in Australia demonstrated the utility of high-dose psyllium given as a premeal supplement (12 g before each of 3 meals) as an adjunct to a short-term, calorie-reduced weight loss program. Other studies have demonstrated conflicting results from supplemental fiber in short-term weight management $[71,85]$.

\section{Conclusions}

Most clinicians in the field of obesity medicine agree that dietary intervention for long-term weight management should include practical eating strategies that promote and maintain satiety to improve compliance and to minimize discomfort in patients working to reduce energy intake. In this regard, many clinicians now recommend volumetric, low-calorie-density, low GL diets supplemented with moderate amounts of protein. Increasing the intake of fiber by consuming more high-fiber foods should play a central role in this regard. These changes alone may not be sufficient to bring about long-term weight reduction [85]. Supplementation of the diet with functional fiber supplements may significantly augment high-fiber eating strategies by further promoting satiety and reducing cardiometabolic risk factors. Long-term clinical trials looking at the optimal form, quantity, and frequency of dietary fiber supplements are greatly needed to clarify their potential in the long-term management of obesity.

Disclosure Conflicts of interest: M.R. Lyon: has been a consultant for Factors Group Inc.; V. Kacinik: is employed by the Canadian Center for Functional Medicine; and has received grant support, honoraria, and travel/accommodations expenses covered or reimbursed from Factors Group Inc.

Open Access This article is distributed under the terms of the Creative Commons Attribution License which permits any use, distribution, and reproduction in any medium, provided the original author(s) and the source are credited.

\section{References}

Papers of particular interest, published recently, have been highlighted as:

- Of importance

•• Of major importance

1. Wanders AJ, van den Borne JJ, de Graaf C, Hulshof T, Jonathan $\mathrm{MC}$, Kristensen $\mathrm{M}$, et al. Effects of dietary fibre on subjective appetite, energy intake and body weight: a systematic review of randomized controlled trials. Obes Rev. 2011;12(9):724-39. doi:10.1111/j.1467-789X.2011.00895.x. Epub 2011 Jun 16.

2. Dietary, Functional and Total fiber, In Dietary reference intakes for energy, carbohydrate, fiber, fat, fatty acids, cholesterol, protein, and amino acids (macronutrients).US Department of Agriculture, National Agricultural Library and National Academy of Sciences, Institute of Medicine, Food and Nutrition Board. Washington, DC: National Academies Press; 2005. p. 339-421.

3. Institute of Medicine. Dietary Reference Intakes: proposed definitions of dietary fiber. Washington: National Academy Press; 2001. 
4. The Codex Alimentaris Commision of the World Health Organization and the Food and Agriculture Organization of the United Nations. Report Of The 30th Session of the Codex Committee on Nutrition and Foods for Special Dietary Uses. Cape Town, South Africa. 3-7 November 2008

5. Dietary intake of vitamins, minerals, and fiber of persons ages 2 months and over in the United States: Third National Health and Nutrition Examination Survey, Phase 1, 1988-1991. Advance Data from Vital and Health Statistics, No. 258. Hyattsville, MD: National Center for Health Statistics.

6. Lindberg S. Food and western disease; health and nutrition from an evolutionary perspective. Hoboken: Wiley; 2010.

7. Timm D, Slavin J. Dietary fiber and the relationship to chronic diseases. Am J Lifestyle Med. 2008;2:233-40.

8. Hur IY, Reicks M. Relationship between Whole-Grain Intake, Chronic Disease Risk Indicators, and Weight Status among Adolescents in the National Health and Nutrition Examination Survey. J Am Diet Assoc. 2011. [Epub ahead of print], 1999-2004.

9. Mälkki A. Physical properties of dietary fiber as keys to physiological functions. Cereal Foods World. 2001;46:196-9.

10. Edwards CA. The physiological effects of dietary fiber. In: Kritchevsky D, Bonfield C, editors. Dietary fiber in health and disease. St. Paul: Eagan Press; 1995. p. 58-71.

11. de Graaf C, Blom WA, Smeets PA, Stafleu A, Hendriks HF. Biomarkers of satiation and satiety. Am J Clin Nutr. 2004;79:946-61.

12. Hoad CL, Rayment P, Spiller RC, et al. In vivo imaging of intragastric gelation and its effect on satiety in humans. J Nutr. 2004;134:2293-300.

13. Marciani L, Gowland PA, Spiller RC, Manoj P, Moore RJ, Young $\mathrm{P}$, et al. Gastric response to increased meal viscosity assessed by echo-planar magnetic resonance imaging in humans. J Nutr. 2000;130:122-7.

14. Overduin J, Frayo RS, Grill HJ, Kaplan JM, Cummings DE. Role of the duodenum and macronutrient type in ghrelin regulation. Endocrinology. 2005;146:845-50.

15. Dikeman C, Fahey G. Viscosity as related to dietary fiber: a review. Crit Rev Food Sci Nutr. 2006;46:649-63.

16. Koguchi T, Nakajima H, Koguchi H, et al. Suppressive effect of viscous dietary fiber on elevations of uric acid in serum and urine induced by dietary RNA in rats is associated with strength of viscosity. Int J Vitam Nutr Res. 2003;73:369-76.

17. •- Kristensen M, Jensen MG. Dietary fibres in the regulation of appetite and food intake. Importance of viscosity. Appetite. 2011;56(1):65-70. Epub 2010 Nov 27. This review summarizes the evidence supporting the notion that the viscosity of a dietary fiber is preeminent with regard to its effects upon appetite and quantity of food consumed.

18. Ito H, Satsukawa M, Arai E, et al. Soluble fiber viscosity affects both goblet cell number and small intestine mucin secretion in rats. J Nutr. 2009;139:1640-7.

19. Bourne M. Food texture and viscosity: concept and measurement. 2nd ed. San Diego: Academic; 2002.

20. Jenkins DJ, Wolever TM, Leeds AR, et al. Dietary fibres, fibre analogues, and glucose tolerance: importance of viscosity. BMJ. 1978;1:1392-4.

21. Chaudhri O, Small C, Bloom S. Gastrointestinal hormones regulating appetite. Phil Trans Biol Sci. 2006;361:1187-209.

22. - Thomas S, Schauer P. Bariatric surgery and the gut hormone response. Nutr Clin Pract. 2010;25(2):175-82. This paper reviews the evidence that the principle mechanism underlying the response to gastric bypass surgery is related to an increase in the transit of nutrients to the distal bowel. This is thought to improve glucose metabolism and reduce appetite by stimulating secretion of GLP-1 and other appetite-suppressing gut peptides.

23. Flood JE, Rolls BJ. Soup preloads in a variety of forms reduce meal energy intake. Appetite. 2007;49:626-34.
24. ••Roe LS, Meengs JS, Rolls BJ. Salad and satiety. The effect of timing of salad consumption on meal energy intake. Appetite. 2012;58:242-8. Eating a larger salad with meals reduces caloric intake of the whole meal in most people.

25. •- Spill MK, Birch LL, Roe LS, Rolls BJ. Hiding vegetables to reduce energy density: an effective strategy to increase children's vegetable intake and reduce energy intake. Am J Clin Nutr. 2011;94(3):735-41. Epub 2011 Jul 20. We all know that eating more vegetables promotes a reduced caloric intake. This study demonstrates that high-fiber vegetables can be "hidden" in foods resulting in increased vegetable fiber intake.

26. •• Kacinik V, Lyon M, Purnama M, Reimer RA, Gahler R, Green TJ and Wood S. Effect of PGX, a novel functional fibre supplement, on subjective ratings of appetite in overweight and obese women consuming a 3-day structured, low-calorie diet. Nutr Diabetes. (2011);1: e22; doi:10.1038/nutd.2011.18. In this double-blind placebocontrolled crossover trial, we showed that the addition of a highly viscous fiber supplement sprinkled on foods in easily consumed doses reduced hunger and promoted satiety in women consuming a structured 1000-kcal/day diet.

27. •• Rolls BJ. Plenary lecture 1: Dietary strategies for the prevention and treatment of obesity. Proc Nutr Soc. 2010;69:70-9. An excellent review of the use of reduced energy-density diets in weight management.

28. Ello-Martin JA, Roe LS, Ledikwe JH, et al. Dietary energy density in the treatment of obesity: a year-long trial comparing 2 weightloss diets. Am J Clin Nutr. 2007;85:1465-77.

29. Rolls BJ. The relationship between dietary energy density and energy intake. Physiol Behav. 2009;97:609-15.

30. Gibson GR, Roberfroid MB. Dietary modulation of the human colonic microbiota: introducing the concept of prebiotics. J Nutr. 1995;125:1401-12.

31. Roberfroid M. Prebiotics: concept, definition, criteria, methodologies, and products. In: Gibson GR, Roberfroid M, editors. Handbook of prebiotics. Boca Raton: CRC; 2008. p. 39-69.

32. Dewulf EM, Cani PD, Neyrink AM, et al. Inulin-type fructans with prebiotic properties counteract GPR43 overexpression and PPARgamma-related adipogenesis in the white adipose tissue of high-fat diet-fed mice. J Nutr Biochem. 2011;22:712-22.

33. Delzenne NM, Cani PD. Interaction between obesity and the gut microbiota: relevance in nutrition. Annu Rev Nutr. 2011;31:15-31.

34. Gruber C. Prevention of allergy by pro- and prebiotics. Exp Rev Clin Immunol. 2009;5:1-3.

35. Eiwegger T, Stahl B, Haidl P. Prebiotic oligosaccharides: in vitro evidence for gastrointestinal epithelial transfer and immunomodulatory properties. Pediatr Allergy Immunol. 2010;21:1179-88.

36. van der Aa LB, van Aalderen WM, Heymans HS. et al; Synbad Study Group. Synbiotics prevent asthma-like symptoms in infants with atopic dermatitis. Allergy. 2011;66:170-7.

37. Gruber C, van Stuijvenberg M, Mosca F, et al. MIPS 1 Working Group. Reduced occurrence of early atopic dermatitis because of immunoactive prebiotics among low-atopy-risk infants. J Allergy Clin Immunol. 2010;126:791-7.

38. Mallappa RH, Rokana N, Duary RK, Panwar H, Batish VK, Grover $\mathrm{S}$. Management of metabolic syndrome through probiotic and prebiotic interventions. Indian J Endocrinol Metab. 2012;16(1):20-7.

39. Frazier TH, DiBaise JK, McClain CJ. Gut microbiota, intestinal permeability, obesity-induced inflammation, and liver injury. $\mathrm{J}$ Parenter Enteral Nutr. 2011;35(5 Suppl):14S-20. Epub 2011 Aug 1.

40. Maurer AD, Eller LK, Hallam MC, et al. Consumption of diets high in prebiotic fiber or protein during growth influences the response to a high fat and sucrose diet in adulthood in rats. Nutr Metab. 2010;7:77.

41. Veereman-Wauters G, Staelens S, Van de Broek H, et al. Physiological and bifidogenic effects of prebiotic supplements in infant formulae. J Pediatr Gastroenterol Nutr. 2011;52:763-71. 
42. Angelakis E, Armougom F, Million M, Raoult D. The relationship between gut microbiota and weight gain in humans. Future Microbiol. 2012;7(1):91-109.

43. Kaji I, Karaki S, Tanaka R, Kuwahara A. Density distribution of free fatty acid receptor 2 (FFA2)-expressing and GLP-1-producing enteroendocrine $\mathrm{L}$ cells in human and rat lower intestine, and increased cell numbers after ingestion of fructo-oligosaccharide. J Molecular Histol. 2011;42:27-38.

44. Strader AD, Woods SC. Gastrointestinal hormones and food intake. Gastroenterology. 2005;128:175-91.

45. Maljaars PW, Peters HP, Mela DJ, Masclee AA. Ileal brake: a sensible food target for appetite control. A review. Physiol Behav. 2008;95(3):271-81. Epub 2008 Jul 21.

46. Cummings DE. Endocrine mechanisms mediating remission of diabetes after gastric bypass surgery. Int J Obes. 2009;33 Suppl $1: \mathrm{S} 33-40$.

47. Katsuma S, Hirasawa A, Tsujimoto G. Bile acids promote glucagon-like peptide-1 secretion through TGR5 in a murine enteroendocrine cell line STC-1. Biochem Biophys Res Commun. 2005;329:386-90.

48. Reimann F, Ward PS, Gribble FM. Signalling mechanisms underlying the release of glucagon-like peptide-1. Diabetes. 2006;55 Suppl 2:S78-85.

49. Hirasawa A, Tsumaya K, Awaji T, et al. Free fatty acids regulate gut incretin glucagon-like peptide-1 secretion through GPR120. Nat Med. 2005;11:90-4.

50. Tolhurst G, Reimann F, Gribble FM. Nutritional regulation of glucagon-like peptide-1 secretion. J Physiol. 2009;587:27-32.

51. Patti ME, Houten SM, Bianco AC, et al. Serum bile acids are higher in humans with prior gastric bypass: potential contribution to improved glucose and lipid metabolism. Obesity. 2009;17:1671-7.

52. Ichimura A, Hirasawa A, Hara T, Tsujimoto G. Free fatty acid receptors act as nutrient sensors to regulate energy homeostasis. Prostag Other Lipid Mediat. 2009;89:82-8.

53. Lin HC, Zhao XT, Chu AW, Lin YP, Wang L. Fiber-supplemented enteral formula slows intestinal transit by intensifying inhibitory feedback from the distal gut. Am J Clin Nutr. 1997;65:1840-4.

54. Wen J, Phillips SF, Sarr MG, Kost LJ, Holst JJ. PYY and GLP-1 contribute to feedback inhibition from the canine ileum and colon. Am J Physiol. 1995;269:G945-52.

55. Roberts RE, Glicksman C, Alaghband-Zadeh J, et al. The relationship between postprandial bile acid concentration, GLP-1, PYY and ghrelin. Clin Endocrinol. 2011;74:67-72.

56. Knop FK. Bile-induced secretion of glucagon-like peptide-1: pathophysiological implications in type 2 diabetes? Am J Physiol Endocrinol Metab. 2011;299:E10-3.

57. Sánchez D, Miguel M, Aleixandre A. Dietary fiber, gut peptides, and adipocytokines. J Med Food. 2011; [Epub ahead of print]

58. Jones PJ. Dietary agents that target gastrointestinal and hepatic handling of bile acids and cholesterol. J Clin Lipid. 2008;2: S4-10.

59. Wolever TM. Relationship between dietary fiber content and composition in foods and the glycemic index. Am J Clin Nutr. 1990;51 (1):72-5.

60. Kochan AM, Wolever TM, Chetty VT, Anand SS, Gerstein HC, Sharma AM. Glycemic index predicts individual glucose responses after self-selected breakfasts in free-living, abdominally obese adults. J Nutr. 2012;142(1):27-32. Epub 2011 Nov 16.

61. Bao J, Atkinson F, Petocz P, Willett WC, Brand-Miller JC. Prediction of postprandial glycemia and insulinemia in lean, young, healthy adults: glycemic load compared with carbohydrate content alone. Am J Clin Nutr. 2011;93(5):984-96. Epub 2011 Feb 16.

62. Fabricatore AN, Ebbeling CB, Wadden TA, Ludwig DS. Continuous glucose monitoring to assess the ecologic validity of dietary glycemic index and glycemic load. Am J Clin Nutr. 2011;94(6):1519-24. Epub 2011 Nov 9
63. Krog-Mikkelsen I, Sloth B, Dimitrov D, Tetens I, Björck I, Flint A, et al. A low glycemic index diet does not affect postprandial energy metabolism but decreases postprandial insulinemia and increases fullness ratings in healthy women. J Nutr. 2011;141 (9):1679-84. Epub 2011 Jul 20.

64. Esfahani A, Wong JM, Mirrahimi A, Villa CR, Kendall CW. The application of the glycemic index and glycemic load in weight loss: A review of the clinical evidence. IUBMB Life. 2011;63 (1):7-13. doi:10.1002/iub.418.

65. •- Larsen TM, Dalskov SM, van Baak M, Jebb SA, Papadaki A, Pfeiffer AF, et al. Diets with high or low protein content and glycemic index for weight-loss maintenance. $\mathrm{N}$ Engl J Med. 2010;363(22):2102-13. This discusses the Diogenes trial, a landmark study that demonstrated superiority of a low GI, moderately high protein diet in the maintenance of weight loss.

66. Gögebakan O, Kohl A, Osterhoff MA, van Baak MA, Jebb SA, Papadaki A, et al. Effects of weight loss and long-term weight maintenance with diets varying in protein and glycemic index on cardiovascular risk factors: the diet, obesity, and genes (DiOGenes) study: a randomized, controlled trial. Circulation. 2011;124 (25):2829-38. Epub 2011 Nov 21.

67. Krishnamurthy VM, Wei G, Baird BC, Murtaugh M, Chonchol $\mathrm{MB}$, Raphael KL, et al. High dietary fiber intake is associated with decreased inflammation and all-cause mortality in patients with chronic kidney disease. Kidney Int. 2012;81(3):300-6. doi:10.1038/ ki.2011.355. Epub 2011 Oct 19.

68. Chuang SC, Vermeulen R, Sharabiani MT, Sacerdote C, Fatemeh $\mathrm{SH}$, Berrino F, et al. The intake of grain fibers modulates cytokine levels in blood. Biomarkers. 2011;16(6):504-10. doi:10.3109/ 1354750X.2011.599042. Epub 2011 Aug 3.

69. Sánchez D, Quiñones M, Moulay L, Muguerza B, Miguel M, Aleixandre A. Soluble fiber-enriched diets improve inflammation and oxidative stress biomarkers in Zucker fatty rats. Pharmacol Res. 2011;64(1):31-5. Epub 2011 Feb 22.

70. Lyon M, Wood S, Pelletier X, Donazzolo Y, Gahler R, Bellisle F. Effects of a 3-month supplementation with a novel soluble highly viscous polysaccharide on anthropometry and blood lipids in nondieting overweight or obese adults. J Hum Nutr Diet. 2011;24 (4):351-9.

71. • Brand-Miller JC, Atkinson FS, Gahler RJ, Kacinik V, Lyon MR, Wood S. Effects of PGX, a novel functional fibre, on acute and delayed postprandial glycaemia. Eur J Clin Nutr. 2010;64:148893. We demonstrated the effect of consuming varying doses of a highly viscous fiber supplement on the GI.

72. Jenkins AL, Kacinik V, Lyon M, Wolever TM. Effect of adding the novel fiber, PGX, to commonly consumed foods on glycemic response, glycemic index and GRIP: a simple and effective strategy for reducing post prandial blood glucose levels-a randomized, controlled trial. Nutr J. 2010;9:58.

73. •• Jenkins AL, Kacinik V, Lyon M, Wolever TM. Reduction of postprandial glycemia by the novel viscous polysaccharide PGX, in a dose-dependent manner, independent of food form. J Am Coll Nutr. 2010;29:92-8. We showed that it is possible to substantially reduce the GI of commonly consumed foods with the addition of small doses of a highly viscous dietary fiber.

74. Vuksan V, Panahi S, Lyon M, et al. Viscosity of fiber preloads affects food intake in adolescents. Nutr Metab Cardiovasc Dis. 2009;19:498-503.

75. Brand-Miller JC, Atkinson FS, Gahler RJ, Kacinik V, Lyon MR, Wood S. Effects of added PGX ${ }^{\circledR}$, a novel functional fibre, on the glycaemic index of starchy foods. Br J Nutr. 2011;10:1-4.

76. Reimer RA, Pelletier X, Carabin IG, et al. Differences in faecal short chain fatty acids in healthy subjects consuming placebo versus the functional fibre, PolyGlycopleX ${ }^{\circledR}$. J Hum Nutr Diet. 2012; doi: 10.1111/j.1365-277X.2012.01230.x. [Epub ahead of print] 
77. Pelletier X, Carabin IG, Lyon M, et al. Increased plasma PYY levels following supplementation with the functional fiber PolyGlycopleX in healthy adults. Eur J Clin Nutr. 2010;64:1186-91.

78. Grover GJ, Koetzner L, Wicks J, Gahler RJ, Lyon MR, Reimer RA, et al. Effects of the soluble fiber complex PolyGlycopleX on glucose homeostasis and body weight in young zucker diabetic rats. Front Pharmacol. 2011;2:47. Epub 2011 Sep 7.

79. Grover GJ, Koetzner L, Wicks J, Gahler RJ, Lyon MR, Reimer RA, et al. Effects of the soluble fiber complex PolyGlycopleX ${ }^{\circledR}$ $\left(\mathrm{PGX}^{\circledR}\right)$ on glycemic control, insulin secretion, and GLP-1 levels in Zucker diabetic rats. Life Sci. 2011;88(9-10):392-9. Epub 2010 Nov 30.

80. Position of the American Dietetic Association: Health implications of dietary fiber. J Am Diet Assoc. 2002;102:993-1000

81. Tucker LA, Thomas KS. Increasing total fiber intake reduces risk of weight and fat gains in women. J Nutr. 2009;139(3):576-81. Epub 2009 Jan 21.
82. Koh-Banerjee P, Franz M, Sampson L, Liu S, Jacobs Jr DR, Spiegelman D, et al. Changes in whole-grain, bran, and cereal fiber consumption in relation to 8 -y weight gain among men. Am J Clin Nutr. 2004;80(5):1237-45.

83. •• Pal S, Khossousi A, Binns C, et al. The effect of a fibre supplement compared to a healthy diet on body composition, lipids, glucose, insulin and other metabolic syndrome risk factors in overweight and obese individuals. Br J Nutr. 2011;105:90-100. Pal et al. demonstrate the usefulness of psyllium supplementation in short-term weight loss.

84. Howarth NC, Saltzman E, McCrory MA, et al. Fermentable and nonfermentable fiber supplements did not alter hunger, satiety or body weight in a pilot study of men and women consuming selfselected diets. J Nutr. 2003;133:3141-4.

85. Saquib N, Natarajan L, Rock CL, Flatt SW, Madlensky L, Kealey $\mathrm{S}$, et al. The impact of a long-term reduction in dietary energy density on body weight within a randomized diet trial. Nutr Cancer. 2008;60(1):31-8. 